\title{
Vascular endothelial growth factor affects dendritic cell activity in hypertensive disorders of pregnancy
}

\author{
JING WANG $^{1}$, YU-MEI TAO ${ }^{2}$, XIAO-YAN CHENG ${ }^{3}$, TIAN-FENG ZHU ${ }^{3}$, \\ ZHI-FANG $\mathrm{CHEN}^{4}$, $\mathrm{HUI} \mathrm{YAO}^{1}$ and LIANG-XIANG SU ${ }^{1}$ \\ Departments of ${ }^{1}$ Laboratory Medicine, ${ }^{2}$ Pathology, ${ }^{3}$ Obstetrics and ${ }^{4}$ Nursing, \\ Nantong Women and Children Health Care Hospital, Nantong, Jiangsu 226018, P.R. China
}

Received July 18, 2014; Accepted March 26, 2015

DOI: $10.3892 / \mathrm{mmr} .2015 .3783$

\begin{abstract}
Vascular endothelial growth factor (VEGF) activity is involved in the growth and stability of the placenta, and its signaling has been implicated in the development of pregnancy-induced hypertension (PIH). The present study sought to evaluate VEGF levels and dendritic cell (DC) profiles in patients with PIH, and to investigate the effects of VEGF expression on DC phenotypes. The present study assessed 162 patients, 112 of whom were diagnosed with PIH. Serum VEGF was measured by ELISA, while myeloid DC (mDC; (Lin1-HLA-DR+CD11c+) and plasmacytoid DC (pDC; Lin1-HLA-DR+CD123+) counts were determined using flow cytometry. In order to determine the effect of VEGF treatment on DC phenotypes, immature DCs (iDCs) were separated from monocytes by culturing in the presence of cytokines (GM-CSF, IL-4), and then pretreated with VEGF or lipopolysaccharide (LPS). The phenotype of dendritic cells (CD14, CD80, CD83, or CD86) was determined by flow cytometry. The levels of VEGF in the serum of patients with PIH were significantly lower than those in control subjects $(\mathrm{P}<0.05)$. The percentage of pDCs found in the serum of patients with preeclampsia was significantly lower than that in the other groups. The percentage of mDCs in the serum of patients with preeclampsia and eclampsia was significantly higher than that in the control and hypertensive disorder groups $(\mathrm{P}<0.05)$. The percentage of mDCs was significantly negatively correlated with the levels of VEGF in the preeclamptic and eclamptic patients $(r=-0.34$ and $r=-0.42$, respectively; $P<0.05)$. Detected levels of CD80, CD83 and CD86 in DCs treated with VEGF were significant lower than those in DCs treated with LPS alone $(\mathrm{P}<0.05)$. In conclusion, abnormal expression of VEGF and an altered dendritic cell profile may be involved in the development of PIH.
\end{abstract}

Correspondence to: Miss. Liang-Xiang Su, Department of Laboratory Medicine, Nantong Women and Children Health Care Hospital, 399 Shiji Road, Nantong, Jiangsu 226018, P.R. China E-mail: ntsulx@163.com

Key words: pregnancy-induced hypertension, vascular endothelial growth factor, dendritic cells

\section{Introduction}

Hypertensive disorders of pregnancy exert profound effects on maternal and infant health. Together, gestational hypertension, preeclampsia, eclampsia, chronic hypertension complicated by preeclampsia and chronic hypertension have an incidence of $9.4 \%$ in China and a worldwide incidence of $7-12 \%(1,2)$. Pregnancy-induce hypertension (PIH) disorders are a leading cause of morbidity and mortality in pregnant and parturient women, and in perineonates, and an understanding of their etiology is a significant concern within obstetrics. A number of studies have suggested roles for the placenta and the immune system in the development of these disorders (3-6).

One candidate protein that functions in the placenta as well as in the regulation of the immune system, is vascular endothelial growth factor (VEGF). VEGF is the most active vascular growth factor in the vascularization of the placenta (7), and has been shown to be involved in the physiological and pathological conditions of hypertension in pregnancy (8). VEGF also contributes to the development of dendritic cells (DCs), which are initiators of the immune response that play an important role in regulating the innate immune system (9). DCs are a heterologous population of cells, which are differentiated from CD34+ hematopoietic progenitor cells (10). Immature DCs (iDCs) have the ability to migrate and, during this process, to achieve activation and functional maturation. It has been reported that the VEGF receptor, fms-related tyrosine kinase 1 (FLT-1), is present on the surface of CD34+ cells $(11,12)$, and that VEGF binds to FLT-1, kinase insert domain receptor/fetal liver kinase 1 (KDR/FLK-1), and FLT-4 receptors (13). Upon binding to FLT-1, VEGF inhibits the activity of the transcription factor, nuclear factor $\kappa \mathrm{B}(\mathrm{NF}-\kappa \mathrm{B})$, blocking the differentiation of hematopoietic stem cells into DCs. Thus, VEGF may contribute to the development of PIH by blocking the differentiation of stem cells into DCs.

The present study sought to investigate the correlation between VEGF expression and DCs in the pathogenesis of hypertensive disorders in pregnancy, by comparing levels of VEGF and DCs in the peripheral blood of patients with hypertensive disorders, as well as evaluating the effect of VEGF on DC phenotypes, their ability to secrete cytokines and the stimulation of primary T-cell activation. 


\section{Materials and methods}

Study participants. The current study recruited 112 patients undergoing treatment in the Division of Obstetrics between December 2012 and December 2013 (mean age, 27.8 2.5 years; mean gestational age, $34.1 \pm 2.3$ weeks). Of these, 46 patients were diagnosed with gestational hypertension, 41 were diagnosed with preeclampsia and 25 were diagnosed with eclampsia. The study included 50 healthy pregnant women (mean age, 27.7 \pm 3.1 years; mean gestational age, $33.7 \pm 1.1$ weeks) as a control group. Among the observation groups (pregnancy-induced hypertension, preeclampsia, and eclampsia), differences in maternal and gestational ages were not statistically significant, and patients had no other obstetric or medical complications, or histories of autoimmune disorders.The present study was approved by the Ethics Committee of Nantong Women and Children Health Care Hospital (Nantong, China) and all patients provided informed consent.

Antibodiesandreagents. The antibodiesusedinthe presentstudy were mouse monoclonal antibodies $(\mathrm{mAb})$ used at a dilution of 1:20 and provided by eBioscience Inc. (San Diego, CA, USA). The antbodies were as follows: Phycoerythrin (PE)-labeled anti-human CD123 antibodies (IgG1, cat. no. 12-1239), fluoresein isothiocyanate (FITC)-labeled anti-human lineage cocktail 1 (Lin 1; IgG2b, cat. no.22-7778), FITC-labeled antihuman CD80 (IgG1, cat. no. 11-0809), anti-human interferon- $\gamma$ (IFN- $\gamma$; IgG1, cat. no. 53-7319), anti-human CD86 (IgG2b, cat. no. 14-0869); FITC-labeled anti-human CD83 (IgG1, cat. no. 11-0839), anti-human CD14 (IgG1, cat. no. 14-0149), PerCy5.5-labeled anti-human HLA-DR antibody (IgG2b, cat. no. 45-9956), allophycocyanin (APC)-labeled anti-human CD11C antibody (IgG1, cat. no. 17-0116), Isotype Control PerCP-Cy5.5 (mAb IgG2b, cat. no. 45-4732), Isotype Control APC (mAb IgG1, cat. no. 17-4717), Isotype Control PE (mAb $\mathrm{IgG1}$, cat. no. 12-4717), Isotype Control FITC (mAb IgG2b, cat. no. 11-4732). Monensin, ionomycin, and phorbol-12-myristate-13-acetate (PMA; Sigma-Aldrich, St. Louis, MO, USA) were used for blocking and washing and the cells were cultured in RPMI-1640 culture medium (Gibco Life Technologies, Gaithersburg, MD, USA).

Detection of serum VEGF. Serum VEGF was detected using an enzyme-linked immunosorbent assay (ELISA), according to the manufacturer's instructions. The absorbance at $450 \mathrm{~nm}$ was measured using an ELISA microplate reader (iMark; Bio-Rad, Hercules, CA, USA) in order to determine the concentration of VEGF in each sample.

Detection of dendritic cells. Whole blood $(50 \mu \mathrm{l})$ was obtained from each subject and anticoagulated with heparin. PerCy5.5-labeled anti-human HLA-DR, FITC-labeled anti-human Lin 1, APC-labeled anti-human CD11C, PE-labeled anti-human CD123, APC-labeled IgG1 isotype control, and PE-labeled IgG1 isotype control antibodies were added to each sample. After hybridizing in darkness for $30 \mathrm{~min}, 500 \mu \mathrm{l}$ hemolytic agent was added and mixed, and samples were placed in darkness for five minutes. Samples were then washed three times using PBS, following which $300 \mu \mathrm{l}$ of $20 \mathrm{~g} / \mathrm{l}$ paraformaldehyde (PFA; Sigma-Aldrich) was added. Samples were then processed by flow cytometry in order to detect plasmacytoid dendritic cells (pDC; Lin 1-HLA-DR+CD123+) and myeloid dendritic cells (mDC; Lin1-HLA-DR+CD11C+). Data were analyzed using CellQuest Software (Beckton, Dickinson and Company, Franklin Lakes, NJ, USA).

VEGF treatment of dendritic cells. PBMCs from healthy individuals were separated by Ficoll-Hypaque (Sigma-Aldrich), then washed three times using complete RPMI-1640 medium, placed in 6-well plates at a density of $5 \times 10^{6}$ cells $/ 1$, and cultured at $37^{\circ} \mathrm{C}$ in $5 \% \mathrm{CO}_{2}$ for $2 \mathrm{~h}$. Suspended cells were removed and adherent cells were collected after they had been rinsed with RPMI-1640. Adherent cells were treated with culture medium containing cytokines (100 g/l rhIL-4 and $100 \mathrm{~g} / \mathrm{l}$ rhGM-CSF). After 3 days, the cytokines were added again and half of the medium was renewed. On the sixth day, half of the medium was renewed, and immature dendritic cells (iDCs) were obtained and cultured as follows: Group A was treated with $1 \mathrm{mg} / \mathrm{l} \mathrm{LPS}$; and groups B, C and D were treated with $1 \mathrm{mg} / 1$ LPS plus $50 \mathrm{ng} / 1$, $100 \mathrm{ng} / \mathrm{l}$, and $150 \mathrm{ng} / \mathrm{l} \mathrm{VEGF}$, respectively. Following 8 days of culture, suspended cells were collected. The concentration was adjusted to $1 \times 10^{9}$ cells/l using RPMI-1640 medium, and DCs were collected and placed into test tubes. PerCy5.5-labeled anti-human HLA-DR antibodies; FITC-labeled anti-human CD14 and CD83 antibodies; in addition to PerCy5.5-labeled IgG1 isotype control antibodies and FITC-labeled IgG1 isotype control antibodies were added. Following hybridization in darkness for $30 \mathrm{~min}$, DCs were washed three times with PBS and then added to $300 \mu \mathrm{l}$ of $20 \mathrm{~g} / \mathrm{l}$ PFA. Flow cytometry was used to measure the mean fluorescence intensity (MFI) of the different dendritic cell types. CellQuest Software was used to obtain and analyze data.

DC-induced differentiation of autologous ThO cells. Peripheral blood mononuclear cells (PBMCs) from healthy individuals were separated and adherent cells were removed. Nylon wool columns were used to separate CD4+ and T cells. Cells were then incubated with a CD45RA antibody (mAb; IgG2b; cat. no. 14-0458-80; eBioscience; 1:20), and immunomagnetic bead separation was performed in order to obtain CD4+CD45RA+Th0 cells. Cells were resuspended in complete medium, then added to DCs at a ratio of 100:1 and placed into wells of a 24-well plate (each well had a total volume of $1 \mathrm{ml})$. The concentration was adjusted to $1 \times 10^{9}$ cells $/ 1$ using RMPI-1640 medium, and on day four of cell culture. The cells $(\mathrm{DC}+\mathrm{Th} 0)$ were collected and analyzed using flow cytometry (BD Biosciences, Franklin Lakes, NJ, USA) .

Flow cytometry. Lymphocytes were collected after 4 days of growth and cultured in 96-well plates at a concentration of $2 \times 10^{6}$ cells $/ \mathrm{ml}$. Ionomycin and PMA were added to bring the volume in each well to $200 \mu \mathrm{l}$. Cells were then incubated at $37^{\circ} \mathrm{C}$ in $50 \mathrm{ml} / \mathrm{l} \mathrm{CO}_{2}$ for $3 \mathrm{~h}$, then blocked with monensin and cultured again for $2 \mathrm{~h}$. The supernatant was removed by centrifugation at 22,000 $\mathrm{xg}$ for $5 \mathrm{~min}$, and $50 \mu \mathrm{l}$ of the remaining liquid was placed into test tubes. CD8-PerCP (BD Pharmingen, San Diego, CA, USA) was then added. After culture in darkness at $4^{\circ} \mathrm{C}$ for 30 min, cell surface molecules were stained with a monoclonal antibody. The mixture was washed two times using $1 \mathrm{ml}$ 
Table I. Comparison of peripheral blood DC and VEGF levels between observation groups and the control group.

\begin{tabular}{lcccc}
\hline Group & $\mathrm{n}$ & VEGF $(\mathrm{ng} / \mathrm{l})$ & $\mathrm{pDC}(\%)$ & $\mathrm{mDC}(\%)$ \\
\hline Normal pregnancy & 50 & $156.31 \pm 14.11$ & $0.21 \pm 0.09$ & $0.25 \pm 0.10$ \\
Pregnancy-induced hypertension & 46 & $91.70 \pm 18.08^{\mathrm{a}, \mathrm{c}}$ & $0.20 \pm 0.08$ & $0.27 \pm 0.10^{\mathrm{c}}$ \\
Preeclampsia & 41 & $65.30 \pm 16.14^{\mathrm{a}, \mathrm{b}}$ & $0.15 \pm 0.11^{\mathrm{a}, \mathrm{b}}$ & $0.33 \pm 0.13^{\mathrm{a}, \mathrm{b}}$ \\
Eclampsia & 25 & $45.66 \pm 12.25^{\mathrm{a}, \mathrm{b}, \mathrm{c}}$ & $0.18 \pm 0.08$ & $0.35 \pm 0.20^{\mathrm{a}, \mathrm{b}}$
\end{tabular}

${ }^{\mathrm{a}} \mathrm{P}<0.05$ vs. normal pregnancy, ${ }^{\mathrm{b}} \mathrm{P}<0.05$ vs. pregnancy-induced hypertension, ${ }^{\mathrm{c}} \mathrm{P}<0.05$ vs. preeclampsia. $\mathrm{DC}$, dendritic cells; VEGF, vascular endothelial growth factor; pDC, plasmacytoid DC, mDC, myeloid DC.

staining buffer, and the cells were fixed in $500 \mu \mathrm{l}$ of $40 \mathrm{~g} / \mathrm{l} \mathrm{PFA}$ at $4^{\circ} \mathrm{C}$ for $30 \mathrm{~min}$. The mixture was washed two times using $1 \mathrm{ml}$ staining buffer, and $500 \mu \mathrm{l}$ of $1 \mathrm{~g} / \mathrm{l}$ saponin-PBS was then added to each tube. Following cell membrane permeation at $4^{\circ} \mathrm{C}$ for $15 \mathrm{~min}$, the supernatant was removed by centrifugation at $22,000 \mathrm{x} \mathrm{g}$ for $5 \mathrm{~min}$. The cells were then sealed with $20 \mu \mathrm{l}$ of $100 \mathrm{ml} / 1$ bovine serum albumin. IL-4-APC (mAb; IgG1, cat. no. 17-7049; eBioscience, 1:20) and IFN- $\gamma$-PE (mAb; IgG1; cat. no. BMS107; eBioscience; 1:20) were added to test tubes to serve as an isotype control, and intracellular cytokine staining was performed, according to the manufacturer's instructions. Samples were washed with PBS, $300 \mu 1$ of $40 \mathrm{~g} / 1$ PFA was added, and detection was performed using a FACSCalibur flow cytometer (Beckton, Dickinson and Company). Cell Quest Software (Beckton, Dickinson and Company) was used to obtain and analyze data.

Statistical analysis. Data were analyzed using SAS 9.2 (SAS Institute Inc., Cary, NC, USA). Sample groups were compared using Student's t-test and linear correlation analysis. The means of multiple samples were compared using analysis of variance. $\mathrm{P}<0.05$ was considered to indicate a statistically significant difference.

\section{Results}

VEGF levels and DC profiles are significantly altered in the peripheral blood of hypertensive pregnant women. VEGF levels in each hypertensive group were lower than those in the control group (Table I, Fig. 1). In addition, VEGF levels incrementally decreased in samples from each group of hypertensive patients in accordance with disease severity. Analysis of variance and a q-test showed that the differences in VEGF levels among the four groups were statistically significant $(\mathrm{P}<0.05)$.

The percentage of pDCs in the preeclampsia group was significantly lower than that in the control and pregnancy-induced hypertension groups (Table I, Fig. 2). The percentage of mDCs in each observation group was significantly higher than that of the control group, and the $\mathrm{mDC}$ levels in the preeclampsia and eclampsia groups were significantly higher than those in the pregnancy-induced hypertension groups (Table I, Fig. 3).

VEGF expression and $m D C$ levels are negatively correlated in preeclamptic and eclamptic patients. In order to determine whether the observed differences in circulating VEGF and in the population of DCs in patients with PIH are associated, the

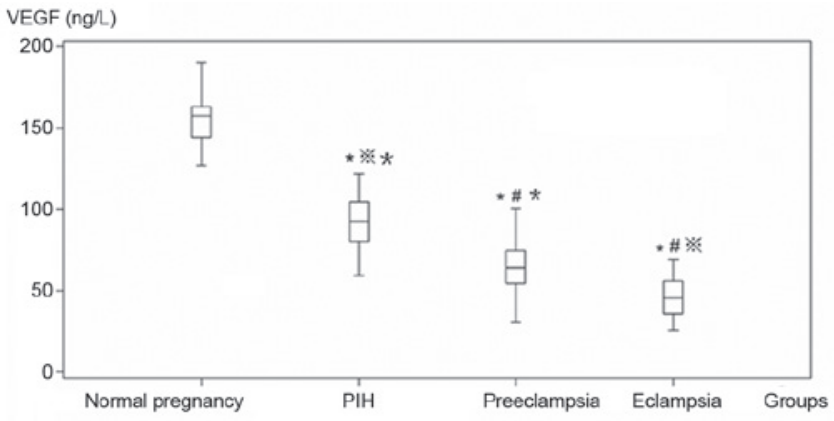

Figure 1. Comparison of VEGF levels between the experimental groups and the control group. ${ }^{*} \mathrm{P}<0.05$, vs. normal pregnancy; ${ }^{\#} \mathrm{P}<0.05$, vs pregnancy-induced hypertension; ${ }^{*} \mathrm{P}<0.05$, vs. preeclampsia, ${ }^{*} \mathrm{P}<0.05$, vs. eclampsia. VEGF, vascular endothelial growth factor.

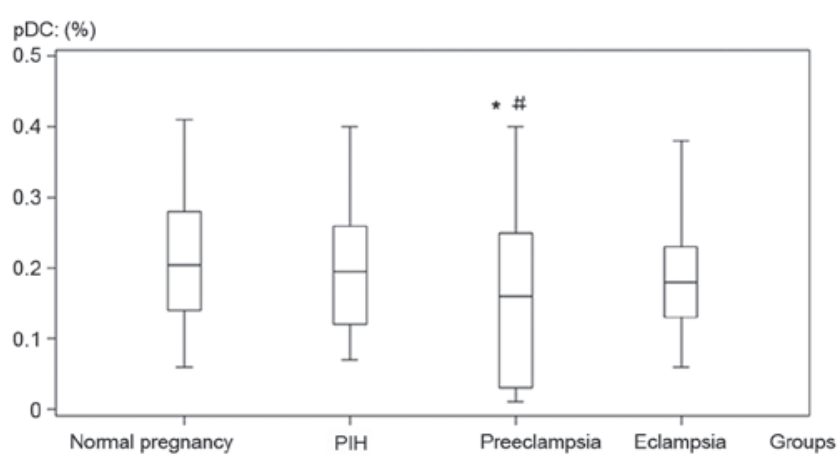

Figure 2. Comparison of pDC levels between the experimental groups and the control group. ${ }^{*} \mathrm{P}<0.05$, vs. normal pregnancy; ${ }^{\#} \mathrm{P}<0.05$, vs. pregnancy-induced hypertension. pDC, plasmacytoid dendritic cell.

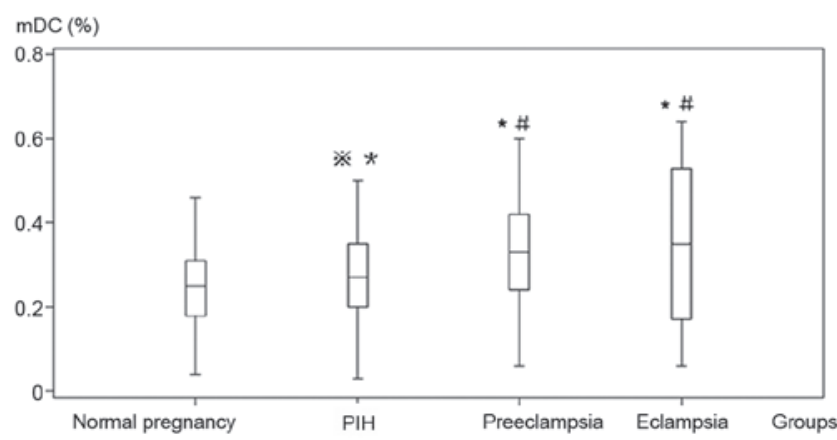

Figure 3. Comparison of $\mathrm{mDC}$ levels between the experimental groups and the control group. ${ }^{*} \mathrm{P}<0.05$, vs. normal pregnancy; ${ }^{\sharp} \mathrm{P}<0.05$, vs. pregnancy-induced hypertension; ${ }^{*} \mathrm{P}<0.05$, vs. preeclampsia, ${ }^{*} \mathrm{P}<0.05$, vs. eclampsia. mDC, myeloid dendritic cell. 
Table II. Correlation between VEGF level and percentage of mDCs in hypertensive patients.

\begin{tabular}{|c|c|c|c|c|}
\hline Group & VEGF (ng/l) & $\mathrm{mDC}(\%)$ & $\mathrm{r}$ & P-value \\
\hline Preeclampsia & $65.30 \pm 16.14$ & $0.33 \pm 0.13$ & -0.34 & $0.029^{\mathrm{a}}$ \\
\hline Eclampsia & $45.66 \pm 12.25$ & $0.35 \pm 0.20$ & -0.42 & $0.034^{\mathrm{a}}$ \\
\hline
\end{tabular}

VEGF, vascular endothelial growth factor; mDC, myeloid dendritic cell.

Table III. Comparison of MFI of DC surface molecules among four different groups.

\begin{tabular}{lccrr}
\hline Group $(\mathrm{n}=5)$ & CD14 & CD80 & CD83 & CD86 \\
\hline A & $11.45 \pm 5.12$ & $60.05 \pm 32.53$ & $138.27 \pm 69.41$ & $89.91 \pm 38.30$ \\
B & $21.45 \pm 8.83^{\mathrm{a}}$ & $34.31 \pm 19.99^{\mathrm{a}}$ & $93.13 \pm 41.92^{\mathrm{a}}$ & $50.26 \pm 43.77^{\mathrm{a}}$ \\
C & $24.79 \pm 7.08^{\mathrm{a}}$ & $24.88 \pm 8.23^{\mathrm{a}, \mathrm{b}}$ & $53.89 \pm 34.45^{\mathrm{a}, \mathrm{b}}$ & $31.86 .30 \pm 25.31^{\mathrm{a}, \mathrm{b}}$ \\
D & $23.11 \pm 7.34^{\mathrm{a}}$ & $23.22 \pm 13.18^{\mathrm{a}, \mathrm{b}}$ & $63.55 \pm 23.36^{\mathrm{a}, \mathrm{b}}$ & $29.53 \pm 25.18^{\mathrm{a}, \mathrm{b}}$
\end{tabular}

${ }^{\mathrm{a}} \mathrm{P}<0.05$, vs. Group A, ${ }^{\mathrm{b}}<0.05$, vs. Group B. A, group A (DC + Th0 cell); B, group B (DC + Th0 cell); C, group C (DC + Th0 cell); D, group D $(\mathrm{DC}+\mathrm{Th} 0$ cell $) ; \mathrm{MFI}$, mean fluorescence intensity; DC, dendritic cell.
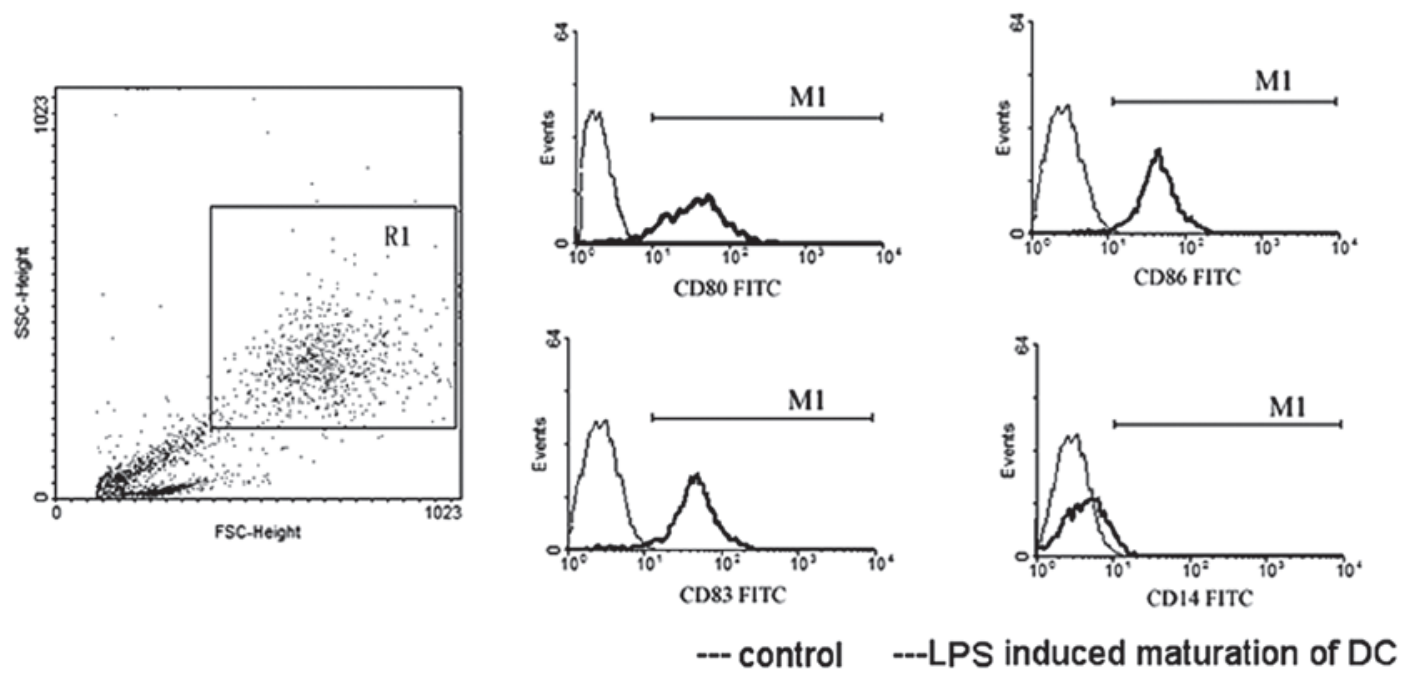

Figure 4. LPS-induced expression of CD14, CD80, CD83 and CD86 in mature DCs. LPS, lipopolysaccharide; DC, dendritic cell.

correlation between VEGF and DCs was analyzed. In the control and pregnancy-induced hypertension groups, VEGF levels were not correlated with the percentage of mDCs. However, in the preeclampsia and the eclampsia groups, VEGF levels were significantly negatively correlated with the percentage of mDCs ( $\mathrm{r}=-0.34$ and -0.42 , respectively; $\mathrm{P}<0.05$; Table II). There was no significant correlation between VEGF levels and the percentage of pDCs among any of the groups.

VEGF affects the maturation and differentiation of DCs. DCs cultured with LPS matured, and consequently exhibited increased expression of CD83, as well as the co-stimulatory molecules CD80 and CD86, while the expression of CD14 decreased. Fig. 4 shows a sample expression profile of CD14, CD80, CD83 and CD86 from cells in group A. The MFI levels of DC surface molecules in the three groups treated

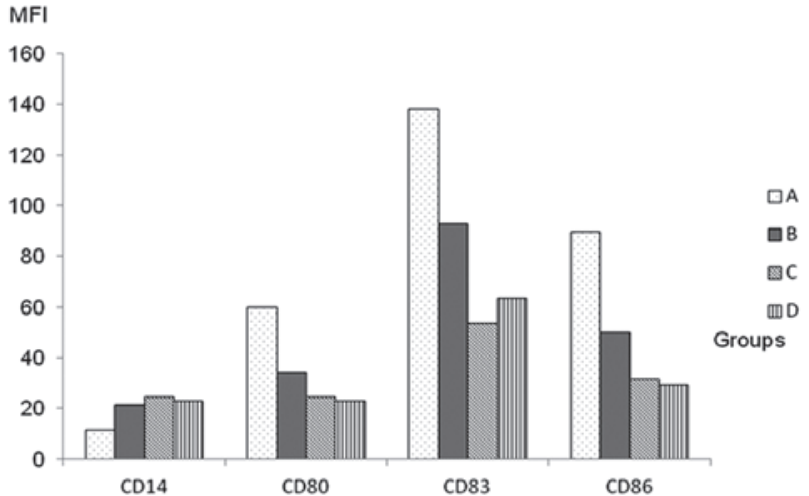

Figure 5. Comparison of MFI of DC surface molecules among four different groups. A, group A (DC + Th0 cell); B, group B (DC + Th0 cell); C, group C (DC + Th0 cell); D, group D (DC + Th0 cell). MFI, mean fluorescence intensity; DC, dendritic cell. 
Table IV. Comparison of IFN- $\gamma$, IL-4 and IFN- $\gamma /$ IL-4 between different groups.

\begin{tabular}{lllr}
\hline Group $(\mathrm{n}=5)$ & IFN- $\gamma(\%)$ & IL-4 $(\%)$ & IFN- $\gamma / \mathrm{IL}-4$ \\
\hline A & $7.51 \pm 1.39$ & $3.59 \pm 0.86$ & $2.38 \pm 0.74$ \\
B & $5.77 \pm 0.85^{\mathrm{a}}$ & $3.14 \pm 0.85$ & $2.32 \pm 0.49$ \\
C & $2.82 \pm 0.76^{\mathrm{a}}$ & $2.96 \pm 0.74$ & $1.16 \pm 0.60^{\mathrm{a}}$ \\
D & $2.72 \pm 0.97^{\mathrm{a}}$ & $2.83 \pm 0.74$ & $1.46 \pm 0.92^{\mathrm{a}}$
\end{tabular}

${ }^{\mathrm{a}} \mathrm{P}<0.05$, vs. group A. A, group A (DC + Th0 cell); B, group B (DC + Th0 cell); C, group C (DC + Th0 cell); D, group D (DC + Th0 cell); IFN- $\gamma$, interferon- $\gamma ; \mathrm{IL}-4$, interleukin-4; DC, dendritic cell.
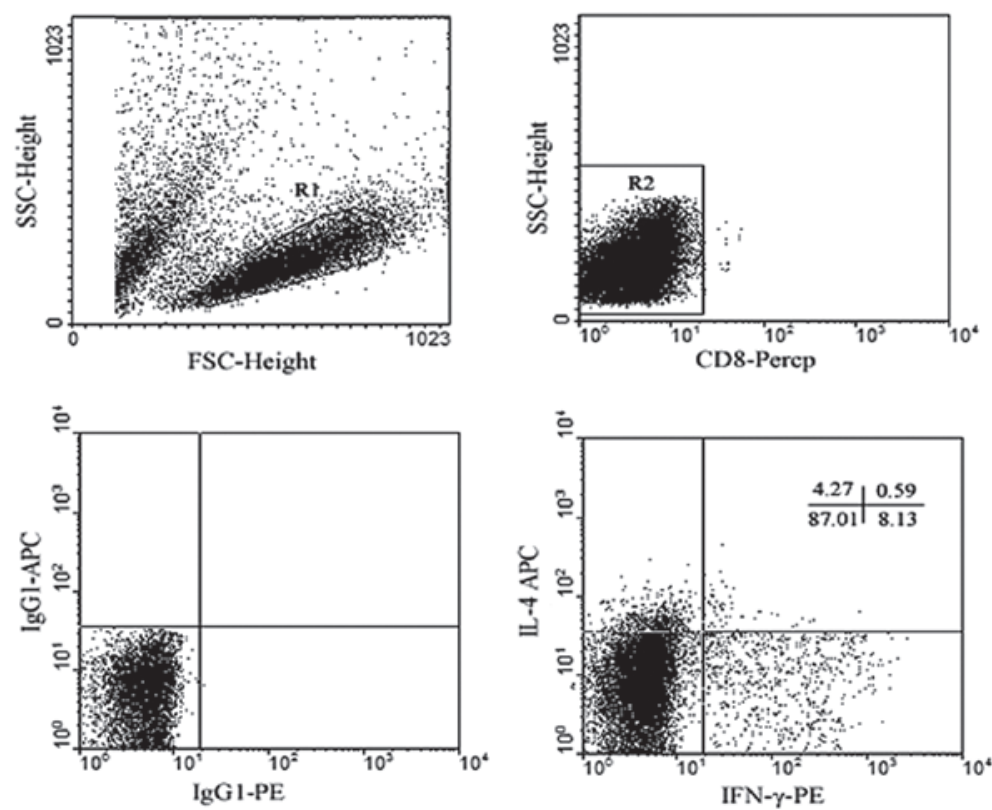

Figure 6. Cytokine expression within cells by flow cytometry. Group A, DC + Th0 cells. DC, dendritic cell; APC, allopycocyanin; PE, phycoerythrin; IL-4, interleukin-4; IFN- $\gamma$, interferon- $\gamma$.

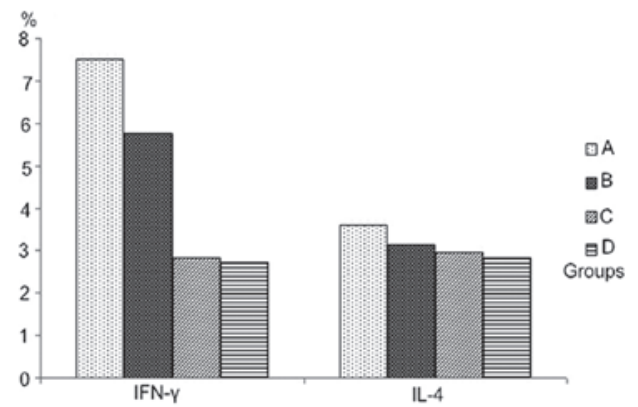

Figure 7. Comparison of IFN- $\gamma$ and IL- 4 between different groups. A, group A $(\mathrm{DC}+\mathrm{Th} 0$ cell); B, group B (DC + Th0 cell); C, group C (DC + Th0 cell); $\mathrm{D}$, group D (DC + Th0 cell). IL-4, interleukin-4; IFN- $\gamma$, interferon- $\gamma$; DC, dendritic cell.

with VEGF were lower than those in group treated with LPS, and their differences were statistically significant $(\mathrm{P}<0.05)$. The differences in the expression of CD14, CD80, CD83 and CD86 between groups C and D were not statistically significant. However, there was a significant difference between these groups and group B (Table III, Fig. 5).

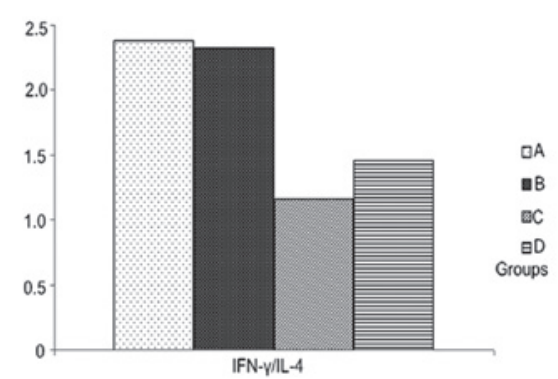

Figure 8. Comparison of IFN- $\gamma /$ IL-4 between different groups. A, group A $(\mathrm{DC}+\mathrm{Th} 0$ cell); B, group B $(\mathrm{DC}+\mathrm{Th} 0$ cell $) ; \mathrm{C}$, group C $(\mathrm{DC}+\mathrm{Th} 0$ cell $) ;$ D, group D (DC + Th0 cell). IL-4, interleukin-4; IFN- $\gamma$, interferon- $\gamma$; DC, dendritic cell.

Cytokines are produced during ThO differentiation induced by DCs. A typical cytokine profile is shown in Fig. 6. The expression of IFN- $\gamma$ in the group treated with LPS alone was the highest, but there were not statistically significant differences in the expression levels of IL-4 among the four groups and the ratios of IFN- $\gamma /$ IL-4 between the group treated with $50 \mathrm{ng} / \mathrm{l}$ VEGF and with LPS. IFN- $\gamma / \mathrm{IL}-4$ ratios in the groups treated with $100 \mathrm{ng} / \mathrm{l}$ 
and $150 \mathrm{ng} / \mathrm{l}$ VEGF were significantly lower than those treated with LPS alone (Table IV, Figs. 7 and 8).

\section{Discussion}

The present study showed that VEGF levels in each hypertensive group were lower than those in the control group, and that the more severe hypertensive cases were associated with lower VEGF levels. The expression of mDCs in peripheral blood samples was higher in the preeclampsia and eclampsia groups than that in the control pregnancy-induced hypertension groups, and was negatively correlated with VEGF levels. Only in the preeclampsia group were $\mathrm{pDCs}$ found to be lower than those in the control and pregnancy-induced hypertension groups, and both differences were statistically significant. However, the correlation of pDCs with VEGF levels was not significant. These results suggest that, at a high concentration, VEGF may inhibit differentiation into $\mathrm{mDCs}$, while it appears to have no inhibitory effects on the level of pDCs.

Notably, Schonkeren et al (14) found that soluble FLT-1 (sFLT-1) expression on the surface of CD14+ macrophages in patients with preeclampsia was increased as a result of the action of VEGF on sFLT-1, thereby inhibiting the differentiation of CD14+ precursor cells into DCs. Further, Stober et al (15) demonstrated that $\mathrm{mDCs}$ stimulate and regulate $\mathrm{T}$ cells to secrete large quantities of the cytokines IL-12, IL-18, TNF- $\alpha$ and IFN- $\gamma$, activating $\mathrm{T}$ cell proliferation and promoting the differentiation of Th0 cells into Th1 cells. Therefore, VEGF may reduce the function and number of mDCs and inhibit the appearance of Th1-type cytokines, thus encouraging a normal pregnancy.

The present study also demonstrated that VEGF may inhibit DC maturation, and that VEGF levels most similar to those observed in the normal pregnancy group, exerted the strongest inhibitory effect. When VEGF was given to autologous primary $\mathrm{T}$ cells, stimulated by DCs, it inhibited the activation of primary T cells stimulated by mDCs. Furthermore, lower VEGF levels resulted in stronger MFI on the surface of DCs, increased DC maturity, and an enhanced ability to produce Th1-type cytokines in stimulated primary $\mathrm{T}$ cells. In addition, the ratio of Th1/Th2 also rose. This is in accordance with a study by Block et al (16) which showed that VEGF reduced the expression of IL-12 $\beta$, which causes CD4 T cells to differentiate into Th1 cells in response to DCs. Chen et al (17) also reported that highly expressed VEGF may reduce the function and number of mDCs, and contribute to immunosuppression.

Numerous studies have illustrated the interaction between VEGF and DCs (18-21), in which VEGF expression leads to abnormal DC phenotypes and functions. The present study suggests that VEGF levels in normal pregnancies may inhibit the maturation of DCs and inhibit the differentiation of Th0 cells into Th1 cells, indicating that the interaction between VEGF and DCs is important in maintaining the maternal-fetal immune balance. These results provide a basis for a greater understanding of the molecular pathogenesis of hypertensive disorders of pregnancy.

\section{Acknowledgements}

This study was supported by Jiangsu Provincial Health Department (grant no. F 201213).

\section{References}

1. Gaio DS, Schmidt MI, Duncan BB, et al: Hypertensive disorders in pregnancy: Frequency and associated factors in a cohort of Brazilian women. Hypertens Pregnancy 20: 269-281, 2001.

2. Lykke JA, Langhoff-Roos J, Sibai BM, et al: Hypertensive pregnancy disorders and subsequent cardiovascular morbidity and type 2 diabetes mellitus in the mother. Hypertension 53: 944-951, 2009

3. Nahar L, Nahar K, Hossain MI, Jahan S and Rahman MM: Placental changes in pregnancy induced hypertension. Mymensingh Med J 22: 684-693, 2013.

4. Nahar L, Nahar K, Hossain MI, Yasmin H and Annur BM: Placental changes in pregnancy induced hypertension and its impacts on fetal outcome. Mymensingh Med J 24: 9-17, 2015.

5. LaMarca B, Cornelius D and Wallace K: Elucidating immune mechanisms causing hypertension during pregnancy. Physiology (Bethesda) 28: 225-233, 2013.

6. Cao X, Wang LL and Luo X: Expression of regulatory $T$ and helper $\mathrm{T}$ cells in peripheral blood of patients with pregnancy-induced hypertension. Clin Exp Obstet Gynecol 40: 502-504, 2013.

7. Kalkunte SS, Mselle TF, Norris WE, et al: Vascular endothelial growth factor $\mathrm{C}$ facilitates immune tolerance and endovascular activity of human uterine NK cells at the maternal-fetal interface. J Immunol 182: 4085-4092, 2009.

8. Tripathi R, Ralhan R, Saxena S, et al: Soluble VEGFR-1 in pathophysiology of pregnancies complicated by hypertensive disorders: The Indian scenario. J Human Hypertens 27: 107-114, 2012.

9. Geissmann F, Auffray C, Palframan R, et al: Blood monocytes: Distinct subsets, how they relate to dendritic cells and their possible roles in the regulation of T-cell responses. Immunol Cell Biol 86: 398-408, 2008.

10. van de Laar L, Buitenhuis M, Wensveen FM, et al: Human CD34-derived myeloid dendritic cell development requires intact phosphatidylinositol 3-kinase-protein kinase B-mammalian target of rapamycin signaling. J Immunol 184: 6600-6611, 2010.

11. Laxmanan S, Robertson SW, Wang E, et al: Vascular endothelial growth factor impairs the functional ability of dendritic cells through Id pathways. Biochem Biophys Res Comm 334: 193-198, 2005.

12. Oyama T, Ran S, Ishida T, et al: Vascular endothelial growth factor affects dendritic cell maturation through the inhibition of nuclear factor-kappa B activation in hemopoietic progenitor cells. J Immunol 160: 1224-1232, 1998.

13. Seetharam L, Gotoh N, Maru Y, et al: A unique signal transduction from FLT tyrosine kinase, a receptor for vascular endothelial growth factor VEGF. Oncogene 10: 135-147, 1995.

14. Schonkeren D, van der Hoorn ML, Khedoe P, et al: Differential distribution and phenotype of decidual macrophages in preeclamptic versus control pregnancies. Am J Pathol 178: 709-717, 2011.

15. Stober D, Schirmbeck R and Reimann J: IL-12/IL-18-dependent IFN- $\gamma$ release by murine dendritic cells. J Immunol 167: 957-965, 2001.

16. Block MS, Nevala WK, Leontovich AA, et al: Differential response of human and mouse dendritic cells to VEGF determines interspecies discrepancies in tumor-mediated $\mathrm{TH} 1 / \mathrm{TH} 2$ polarity shift. Clin Cancer Res 17: 1776-1783, 2011.

17. Chen Z, Varney ML, Backora MW, et al: Down-regulation of vascular endothelial cell growth factor-C expression using small interfering RNA vectors in mammary tumors inhibits tumor lymphangiogenesis and spontaneous metastasis and enhances survival. Cancer Res 65: 9004-9011, 2005.

18. Vicari AP, Treilleux I and Lebecque S: Regulation of the trafficking of tumour-infiltrating dendritic cells by chemokines. Semin Cancer Biol 14: 161-169, 2004.

19. Berger S, Dyugovs.kaya L, Polyakov A, et al: Short-term fibronectin treatment induces endothelial-like and angiogenic properties in monocyte-derived immature dendritic cells: involvement of intracellular VEGF and MAPK regulation. Eur J Cell Biol 91: 640-653, 2012.

20. Mahnke K, Schmitt E, Bonifaz L, et al: Immature, but not inactive: The tolerogenic function of immature dendritic cells. Immunol Cell Biol 80: 477-483, 2002.

21. Sugiyama M, Kakeji Y, Tsujitani S, et al: Antagonism of VEGF by genetically engineered dendritic cells is essential to induce antitumor immunity against malignant ascites. Mol Cancer Ther 10: 540-549, 2011. 